Sugerencia de citación: Rey, M. J. (2022). La reconfiguración de la industria frigorífica en Uruguay, 1980-2015. tiempo\&economía, 9(1), en

DOI:

https://doi.org/10.21789/24222704.1725

\title{
La reconfiguración de la industria frigorífica en Uruguay, 1980-2015*
}

\section{The Reconfiguration of Uruguay's Meat Packing Industry, 1980-2015}

\author{
María José Rey \\ Programa de Historia Económica y Social, \\ Universidad de la República, Uruguay \\ https://orcid.org/0000-0001-9539-5903 \\ majosreyd@gmail.com
}

\footnotetext{
* Este documento incorpora resultados de la tesis de maestría en historia económica de la autora, cuya tutoría estuvo a cargo de Jorge Álvarez Scanniello y José Bervejillo.
}

\section{RESUMEN}

Durante las últimas décadas, la industria frigorífica uruguaya ha experimentado dos reconversiones que abarcaron la ampliación del parque industrial, sustantivas transformaciones en el equipamiento de las plantas, menores cambios en su localización geográfica y la llegada de nuevos actores con nuevas estrategias empresariales. En este trabajo se identifican las principales transformaciones estructurales registradas entre 1980 y 2015 y se efectúa un análisis en términos del desempeño productivo. Los resultados de la investigación sugieren que hacia finales del período de estudio el núcleo duro de la industria frigorífica incluía gran parte del elenco que protagonizó la primera reconversión. No obstante, esta tiene mayor capacidad 
instalada y nuevas tecnologías, es propiedad mayoritariamente de capitales extranjeros y, en algunos casos, opera de forma fusionada.

Palabras clave: industria frigorífica, Uruguay, estructura de mercado, desempeño, estrategia de las firmas, historia económica.

Códigos JEL: L66, N56, L1.

\section{ABSTRACT}

Uruguay's beef industry has experienced two reconversions in recent decades, which have included an expansion of the industrial park, significant changes in industrial equipment, less geographic relocation of plants, and the arrival of new actors with new business strategies. This study examines the changes in the structure and performance of the meat processing industry in this country between 1980 and 2015. Our results suggest that towards the end of the study period the hard core of the beef industry included a large part of the group of plants that led the first reconversion. However, the current business has a larger installed capacity and new technologies, it is mostly owned by foreign capital companies, and in some cases operates in a merged manner.

Keywords: Beef industry, Uruguay, market structure, performance, firm strategy, economic history .

JEL Codes: L66, N56, L1.

\section{INTRODUCCIÓN}

La industria frigorífica (IF) que inauguró la década del ochenta surge tras la reconversión productiva que sobrevino a las medidas de liberalización del sector agropecuario aplicadas en 1978. Las llamadas "medidas de agosto" significaron la culminación de un proceso iniciado dos décadas antes, caracterizado por el giro en la política económica en torno a una estrategia de crecimiento basada en las actividades primario-exportadoras.

Las medidas aplicadas incluyeron (i) la liberalización de los precios del ganado en todas las etapas de comercialización; (ii) la liberalización del abasto y, en consecuencia, el cese de la prohibición de faena por categoría y de las cuotificaciones para abasto e industria; (iii) la sustitución de la 
competencia municipal por el poder ejecutivo en la regulación del abasto; (iv) la libre instalación de plantas, el bajo el cumplimiento de los requisitos higiénico-sanitarios y las condicionantes tecnológicas establecidas; y (v) la supresión del Frigorífico Nacional.

Este conjunto de políticas tuvo fuertes implicaciones en lo que refiere a la estructura de la industria cárnica. Hasta entonces, la IF abarcaba tres segmentos: un grupo de frigoríficos exportadores, con escasa incidencia en el mercado interno (la llamada nueva industria); ${ }^{1}$ las plantas frigoríficas estatales o intervenidas que satisfacían el consumo interno en Montevideo y Canelones (la industria tradicional); ${ }^{2}$ y los mataderos cuyos productos tenían como destino la industria de los embutidos. Las medidas aplicadas implicaron, por un lado, la eliminación del Frigorífico Nacional y la culminación de la participación estatal en las plantas intervenidas — es decir, la desaparición de la industria tradicional-y, por otra parte, el ingreso al mercado de abasto interno de los mataderos habilitados a nivel nacional que antes abastecían la industria de los embutidos.

En este artículo se propone identificar los principales cambios estructurales de la IF entre 1980 y 2015, así como examinar su desempeño productivo. El análisis se efectúa con base en los Anuarios Estadísticos de Faena y Exportación del Instituto Nacional de Carnes (INAC), las Encuestas de Actividad Económica del Instituto Nacional de Estadística (INE) y las Encuestas de Actividades de Innovación de la Agencia Nacional de Investigación e Innovación (ANII). Fuentes secundarias también son consultadas.

La estructura del artículo es la siguiente. En el apartado después de la presente introducción se identifican los principales cambios estructurales de la IF. Posteriormente, se analiza el desempeño productivo. Por último, en el apartado final se presentan las conclusiones del estudio.

La nueva industria se refiere al conjunto de plantas frigoríficas que surgieron tras el cambio de reglas en 1959 que implicó la eliminación del monopolio del Frigorífico Nacional en Montevideo y la autorización a numerosas plantas de faena al mercado de exportación (Buxedas, 1983).

2 La industria tradicional se refiere al conjunto de plantas que protagonizó los primeros 50 años de la industria cárnica. Abarca al Frigorífico Nacional creado en 1928 y los primeros frigoríicos instalados a inicios del siglo XX; en su mayoría gracias al influjo de capitales extranjeros. Estos pasaron a ser propiedad estatal y se abocaron al mercado interno durante la década del sesenta; los frigoríficos Swift, Armour y Castro se convirtieron en los Establecimientos Frigoríficos del Cerro S.A. (EFCSA), mientras que el Frigorífico Anglo pasó a ser el Fray Bentos. 


\section{ESTRUCTURA Y ACTORES}

La primera reconversión de la IF se extendió desde finales de la década de los setenta hasta inicios de los noventa. El parque industrial quedó conformado por la nueva industria, orientada en mayor medida al mercado externo, y por un conjunto de plantas de menor porte, con habilitación para abastecer el mercado doméstico que proliferó tras las "medidas de agosto" de 1978. La nueva industria "ampliada" se diferenciaba bastante de la que había caracterizado las décadas previas en tamaño y número de plantas, especialización, localización geográfica y origen del capital.

Una segunda reconversión comenzó a perfilarse en la segunda mitad de los noventa. En la nueva etapa, la IF continuó operando como oligopsonio competitivo y la empresa privada siguió siendo propietaria del núcleo duro industrial. El capital, no obstante, pasó a manos de extranjeros y entre las estrategias empresariales desplegadas emergió el modelo multiplanta. A continuación se profundiza sobre los principales cambios mencionados.

\section{¿Qué estructura? Número de plantas y capacidad instalada; localización y orientación de mercado; desarrollo tecnológico}

En la tabla 1 se presenta la localización geográfica de las plantas habilitadas a nivel nacional, según número y participación en la faena total, y se informa sobre el número de plantas habilitadas al mercado externo.

\begin{tabular}{|c|c|c|c|c|c|c|c|c|}
\hline \multirow{2}{*}{ Departamento } & \multicolumn{2}{|c|}{1980} & \multicolumn{2}{c|}{1990} & \multicolumn{2}{c|}{2000} & \multicolumn{2}{c|}{2011} \\
\cline { 2 - 10 } & N. ${ }^{0}$ & $\%$ & N. ${ }^{\circ}$ & $\%$ & N..$^{\circ}$ & $\%$ & N..$^{\circ}$ & $\%$ \\
\hline Artigas & 1 & 0,6 & - & - & 1 & 0,2 & 2 & 1,9 \\
\hline Canelones & 14 & 57,5 & 12 & 50,1 & 10 & 54,6 & 9 & 45,7 \\
\hline Cerro Largo & 1 & 2,6 & 2 & 0,7 & 1 & 4,7 & 1 & 3,3 \\
\hline Colonia & 1 & 1,0 & 2 & 3,0 & 1 & 2,2 & 2 & 4,3 \\
\hline Durazno & 1 & 3,7 & 1 & 5,3 & 1 & 7,3 & 3 & 10,3 \\
\hline Flores & - & - & 1 & 4,2 & - & - & 1 & 1,4 \\
\hline Florida & 1 & 4,1 & 2 & 3,1 & - & - & - & - \\
\hline Lavalleja & - & - & - & - & 2 & 2,4 & 2 & 4,2 \\
\hline Maldonado & 2 & 3,1 & 2 & 2,1 & 2 & 0,5 & - & - \\
\hline Montevideo & 6 & 10,9 & 8 & 10,9 & 9 & 7,9 & 8 & 9,9 \\
\hline Paysandú & - & - & 2 & 2,8 & 3 & 3,1 & 4 & 3,1 \\
\hline Río Negro & - & - & - & - & - & - & - & - \\
\hline
\end{tabular}

Tabla 1. Número de plantas de faena habilitadas a nivel nacional por departamento (N. ${ }^{\circ}$ y participación en el nivel de faena total (\%) 
Fuente: elaboración propia a partir de los Anuarios Estadísticos del INAC, Pérez-Arrarte (1993) y las páginas web de algunos frigoríficos.

\begin{tabular}{|c|c|c|c|c|c|c|c|c|}
\hline \multirow{2}{*}{ Departamento } & \multicolumn{2}{|c|}{1980} & \multicolumn{2}{c|}{1990} & \multicolumn{2}{c|}{2000} & \multicolumn{2}{c|}{2011} \\
\cline { 2 - 9 } & N. ${ }^{\circ}$ & $\%$ & N. ${ }^{\circ}$ & $\%$ & N. ${ }^{\circ}$ & $\%$ & N. ${ }^{\circ}$ & $\%$ \\
\hline Rivera & - & - & - & - & - & - & - & - \\
\hline Rocha & - & - & 1 & 0,1 & - & - & 1 & 1,5 \\
\hline Salto & 1 & 5,9 & 2 & 6,0 & 2 & 0,6 & 3 & 5,9 \\
\hline San José & 1 & 4,1 & 3 & 6,6 & 2 & 5,2 & 2 & 2,9 \\
\hline Soriano & - & - & - & - & 1 & 0,4 & 1 & \\
\hline Tacuarembó & 1 & 5,6 & 1 & 3,6 & 2 & 4,7 & 3 & 5,2 \\
\hline Treinta y Tres & - & - & 1 & 1,4 & 2 & 0,2 & 1 & - \\
\hline Sin asignar & 2 & 1,0 & - & - & 5 & 5,7 & - & - \\
\hline Total & 32 & 100 & 40 & 100 & 44 & 100 & 43 & 100 \\
\hline Habilitadas para & 17 & - & 33 & - & 29 & - & 27 & - \\
\hline exportación & 17 & & & & & & & \\
\hline
\end{tabular}

De la tabla 1 surge claramente que el número de establecimientos aumentó, en especial durante la primera década. Las "medidas de agosto" de 1978 explican la duplicación del número de establecimientos y el aumento en un $20 \%$ de la capacidad de faena entre 1978 y 1988 (Pérez-Arrarte, 1993, p. 133). El menor incremento relativo de la capacidad instalada se debe al tamaño de las nuevas plantas. Mientras que los frigoríficos exportadores instalados en los sesenta tenían una capacidad de faena que oscilaba entre 200 y 400 cabezas/jornada, la de los nuevos establecimientos variaba entre 60 y 200 cabezas/jornada (Rocca, n.d., p. 108).

A partir de entonces, el número de establecimientos de faena no varió de forma significativa (tabla 1), aunque la capacidad instalada aumentó y alcanzó 3,5 millones de reses anuales hacia finales del período de estudio (tabla 2). Esto último se explica por la expansión del parque industrial y el incremento del número de plantas de mayor escala (tabla 3) durante la segunda reconversión de la IF. Como se observa en la tabla 2, la capacidad ociosa del parque industrial -históricamente uno de sus puntos críticos- mostró un mejor desempeño hacia finales del período de estudio. 
Tabla 2. Capacidad instalada (millones de reses anuales) y efectiva (\%)

\begin{tabular}{|c|c|c|c|c|c|c|c|c|c|c|c|c|c|c|c|c|}
\hline & 1977 & 1978 & 1979 & 1980 & 1981 & 1987 & 1990 & 1991 & 1992 & 1993 & 1994 & 1995 & 1996 & 1997 & 2007 & 2011 \\
\hline $\mathrm{Cl}$ & 2,1 & 2,1 & 2,1 & 1,5 & 1,5 & 2,5 & 2,5 & 2,7 & 2,4 & 2,5 & 2,3 & 2,2 & 2 & 2,1 & 3 & 3,5 \\
\hline CE & 59 & 49 & 40 & 40 & 48 & 75 & 56 & 43 & 51 & 49 & 65 & 65 & 83 & 94 & 73 & 70 \\
\hline
\end{tabular}

Fuente: elaboración propia con base en Buxedas (1983), PérezArrarte (1984), López (1998), Gabinete Productivo (2009) y Fabani (2011).

\begin{tabular}{|c|c|c|}
\hline Año & $N .^{\circ}$ de plantas de faena de gran porte ${ }^{1}$ & Total plantas de faena habilitadas \\
\hline 1989 & 1 & 36 \\
\hline 2000 & 5 & 44 \\
\hline 2015 & 15 & 42 \\
\hline
\end{tabular}

Tabla 3. Número de plantas de faena de gran escala

En lo que se refiere a la localización de las plantas, 20 de los 40 establecimientos operativos a inicios del período de estudio se ubicaban en Montevideo y Canelones y concentraban casi el $70 \%$ de la faena total (tabla 1). El proceso de concentración geográfica de la faena se inició con

'Capacidad de faena $>150.000$ cabezas por año.

Fuente: elaboración propia con base en Anuarios Estadísticos del INAC, Mondelli (2007) y páginas web de los frigoríficos. la emergencia de la nueva industria y se profundizó a finales de los años setenta, cuando se habilitaron mataderos ubicados al sur del país. Hacia finales del período de estudio la concentración fue menor; siendo los establecimientos ubicados en Montevideo y Canelones los responsables del 56 $\%$ de la faena total.

Por otro lado, la tabla 1 da cuenta de un aumento significativo del número de plantas habilitadas para la exportación durante la primera década de estudio, que tuvo de protagonistas a la nueva industria - que desde sus inicios se orientó al mercado exportador-y a parte del segmento que fue habilitado tras las "medidas de agosto" de 1978. Una vez especializados en el mercado doméstico, estos incurrieron en el internacional.

El proceso de expansión del segmento exportador fue promovido por una activa política estatal en el contexto de inestabilidad económica y política que caracterizó la década del ochenta, tanto en el ámbito doméstico como en el internacional. Créditos subsidiados, refinanciaciones, exenciones fiscales, regulación del mercado interno y apoyo en la comercialización internacional fueron las principales políticas aplicadas. Las plantas de faena 
orientadas al mercado doméstico no contaron con el respaldo estatal recibido por el segmento exportador debido a las ventajas competitivas que en materia de costos tenían los mataderos que atendían principalmente el abasto interno. Este segmento, vinculado a mercados destino de más fácil acceso, tenía una escala más pequeña y flexible, la cual permitía una mayor adecuación al suministro de materia prima, una menor inversión por tonelada de carne producida y menores exigencias en los controles oficiales en materia higiénico-sanitaria, laboral e impositiva (Pérez-Arrarte, 1993).

A partir de algunas entrevistas con empresarios, Pérez-Arrarte (1993) identifica las principales innovaciones tecnológicas introducidas en la IF durante la década del ochenta. Algunas de ellas son comunes a las realizadas en la industria manufacturera y tienen que ver con cambios al rediseño de las plantas, aumentos de escala, exigencias de racionalización y reorganización de capacidades técnicas en las diferentes etapas fabriles. Otras innovaciones son más específicas y se diferencian entre las que refieren a la calidad de los productos y aquellas tendientes a incrementar la productividad del trabajo, asociadas a la incorporación de tecnología ahorradora de mano de obra. Entre las primeras se encuentran los avances en requerimientos técnicos que responden a las condicionantes higiénicas y sanitarias de las plantas. Las mayores transformaciones en esa materia se dieron en los frigoríficos habilitados para exportar al bloque europeo, los cuales introdujeron mejoras en la capacidad y el manejo de frío para obtener un proceso de congelación rápido de los cortes envasados en caja, incursionando además en cortes enfriados envasados al vacío destinados a la Cuota Hilton. En cuanto a la productividad del trabajo, se destacan la introducción de máquinas cuereadoras, el cambio en el desosado - de la utilización de mesas al deshuesado con reses colgadas - y la difusión de nuevo equipamiento técnico como sierras mecánicas portátiles, cuchillas neumáticas y limpiadores de huesos.

Durante la década del noventa los cambios tecnológicos consistieron en mejoras en el diseño de las plantas, inversión en equipamiento y cambios organizacionales que redundaron en un proceso más eficiente de la división del trabajo (Espino \& Salazar, 2000). Al igual que lo notado por Pérez-Arrarte, Espino y Salazar señalan que durante esta década las innovaciones de procesos se dieron en mayor grado en las plantas exportadoras. En igual sentido, Ordeix y Ferreira (2001) afirman que los perfiles tecnológicos, la inversión y el nivel de costos operativos de las plantas se encontraban fuertemente asociados a las exigencias higiénicas y sanitarias impuestas por los mercados 
destino. La introducción de herramientas de análisis de riesgos y control de puntos críticos (como el HACCP), ${ }^{3}$ así como la trazabilidad individual en la fase industrial, ${ }^{4}$ fueron herramientas que se originaron en respuesta a las nuevas condicionantes para acceder a Estados Unidos (EE. UU.) y la Unión Europea (UE). De acuerdo con Laens y Paolino (2004), hacia mediados de la década del 2000 todos los frigoríficos exportadores cumplían con las normas de inocuidad y calidad exigidas internacionalmente, como el HACCP y el EUREP G.A.P. ${ }^{5}$

Estos avances tecnológicos, incrementales y acumulativos, principalmente de las empresas exportadoras, sustentan lo diagnosticado por Paolino (2004) sobre la presencia de una estructura fuertemente segmentada en función de factores tecnológicos y organizacionales vinculados a las exigencias higiénicas y sanitarias del mercado internacional.

Durante su segunda reconversión la IF volvió a experimentar un salto en materia de capacidad instalada (tabla 2), e incorporó innovaciones vinculadas a la gestión de la cadena de frío (túneles de enfriamiento) y el mantenimiento de procedimientos para garantizar la inocuidad (Bittencourt et al., 2011). Con base en entrevistas y encuestas a informantes calificados, Sanguinetti et al. (2018) identifican un conjunto de tecnologías emergentes y significativas en la IF (tabla 4).

Las innovaciones identificadas incluyen las tecnologías de información y comunicación (TIC) y responden a normativas que hacen a la inocuidad y calidad de las carnes. Las TIC constituyen herramientas fundamentales para el seguimiento de procesos - control de riesgos, tipificación automática de las canales, sistema de cajas negras-, la comercialización de productos y la gestión de las firmas. Dada la obligación que tienen las mayores empresas exportadoras de asumir estándares de calidad internacionales, los entrevistados sostienen que son estas las que innovan en normas de seguridad laboral e inocuidad alimentaria y en infraestructura para garantizar el bienestar animal y la trazabilidad. A continuación, se

3 El Análisis de Peligros y Puntos Críticos de Control (HACCP, por sus siglas en inglés) es una herramienta de gestión de la calidad en la producción de alimentos.

$4 \quad$ La trazabilidad individual surge a finales de la década de 1990 para atacar la evasión fiscal. La herramienta fue cobrando mayor interés por su uso potencial para hacer más transparente la información entre eslabones. Es tras la implementación del Sistema Electrónico de Información de la Industria Cárnica (SEIIC), conocido como Cajas Negras, que en 2008 se logra el empalme de la fase industrial con la trazabilidad en la fase primaria. (Sanguinetti, 2013).

5 En 1997, y como iniciativa de un grupo de minoristas, se creó en Reino Unido EUREP G.A.P. (desde 2007, Global G.A.P.), un programa privado de certificación voluntaria para las buenas prácticas agrícolas, actualmente de alcance global. Véase: https://www.globalgap.org/es/who-we-are/ about-us/history/ 
Tabla 4. Tecnologías emergentes y significativas de la $\mathrm{IF}^{1}$

1 Por tecnologías

emergentes se refiere a

"tecnologías en desarrollo,

en etapa precomercial,

recientemente introducidas

en el mercado o con

bajo grado de difusión

(adquisición y uso),

independientemente

del tiempo que están

en el mercado". Por

tecnologías significativas

se refiere a aquellas que

"sin ser emergentes,

tienen efectos continuos

sobre los procesos de

producción, así como sobre

los perfiles profesionales

y sus competencias",

pudiendo haberse

incorporado hace tiempo

pero dada su actualización

siguen generando

transformaciones

(Sanguinetti et al., 2018, p.

11).

Fuente: tomado de Sanguinetti et al. (2018, pp. 31-32). profundiza en el segmento exportador para efectos de identificar las empresas que han liderado los cambios.

\begin{tabular}{ll}
\hline Sistema de pesaje dinámico & $\begin{array}{l}\text { Hardware y software para medir y registrar con precisión el peso de los } \\
\text { animales vivos en movimiento y las piezas de los animales en el proceso de } \\
\text { faena. }\end{array}$ \\
\hline Máquinas para extracción de cuero & $\begin{array}{l}\text { Equipamiento automático que permite colaborar en la extracción del cuero } \\
\text { de las canales. }\end{array}$ \\
\hline Sistema de tipificación bovina & $\begin{array}{l}\text { Tecnología (con base en inteligencia artificial) que permite la clasificación } \\
\text { de la media res en dos medidas y escalas independientes (conformación y } \\
\text { terminación). }\end{array}$ \\
\hline $\begin{array}{l}\text { Sistema automático para descontami- } \\
\text { nación bacteriana de las canales }\end{array}$ & $\begin{array}{l}\text { Medidas y procesos tecnológicos para mitigar la contaminación microbiana } \\
\text { en las canales (como tecnologías de aspersión de productos químicos }\end{array}$ \\
higiénicos).
\end{tabular}

\section{¿Cuáles actores? Grado de concentración y propiedad del capital}

Siguiendo a Trylesinski (1981, p. 118), un conjunto de empresas líderes, pertenecientes a la nueva industria, emergió a finales de los años setenta. El llamado "grupo concentrador" incrementó de 43 a 56 \% su participación en la faena total entre 1978 y 1980 . Este grupo, conformado por los frigoríficos Canelones, Carrasco, La Caballada, San Jacinto y Tacuarembó, era además el que concentraba los mayores niveles de ocupación; cada planta empleaba más de 600 trabajadores (Rocca, n.d., p. 116).

A mediados de la década del noventa, un estudio sobre la competitividad de la carne bovina realizado en el marco del Proyecto COMISEC/ BID-UE-PNUD destacaba a los frigoríficos Colonia, Tacuarembó, Carrasco, San Jacinto y La Caballada, y lo denominaba "El club de los cinco". El estudio se refiere a ciertas características que compartía "El club de los cinco" que los diferenciaba del resto de las plantas: (i) una estrategia de exportación fuertemente orientada hacia la UE e Israel; (ii) una gama similar de productos 
(trozos de cuartos traseros enfriados, corte congelados "finos" como el lomo o bife angosto, y cortes delantero tipo kosher); (iii) un nivel tecnológico elevado; (iv) instalaciones para la faena de ovinos (además de vacunos); (v) vínculos con cadenas internacionales de fast food; (vi) linealidad en sus procesos; (vii) Niveles de endeudamiento comparables y en proceso de negociación; (viii) sistemas eficientes de empaque al vacío; y (ix) circuitos de distribución propia en el mercado interno. En el estudio se distinguen otras tres plantas exportadoras, Canelones, Las Piedras y Elbio Pérez Rodríguez, por su acceso a la UE y EE. UU., y porque tenían una participación creciente en la faena y la exportación.

La información provista por los trabajos referidos corresponde con los datos de la tabla 5, en donde se constata una gran permanencia de las empresas que ocupan los primeros lugares del ranking de faena y exportación. Entre las plantas líderes se ubica el "grupo concentrador" a que hacía referencia Trylesinski (1981), así como “El club de los cinco" (ampliado) mencionado en el estudio de la COMISEC.
Tabla 5. Nivel de concentración, según nivel de faena y valor exportado (\%)

\begin{tabular}{|c|c|c|c|c|c|c|c|c|c|c|c|}
\hline \multicolumn{3}{|c|}{1980} & \multicolumn{3}{|c|}{1985} & \multicolumn{3}{|c|}{1990} & \multicolumn{3}{|c|}{1995} \\
\hline Frigorífico & Faena & Exp. & Frigorífico & Faena & Exp. & Frigorífico & Faena & Exp. & Frigorífico & Faena & Exp. \\
\hline Tacuarembó & 10,6 & 20,2 & Carrasco & 9,6 & 14,3 & Tacuarembó & 9,1 & 11,4 & Canelones & 8,1 & 16,0 \\
\hline San Jacinto & 9,5 & 14,8 & Tacuarembó & 7,0 & 11,2 & San Jacinto & 9,0 & 11,1 & San Jacinto & 10,6 & 13,8 \\
\hline Carrasco & 6,8 & 10,8 & San Jacinto & 7,5 & 10,5 & Carrasco & 8,5 & 10,2 & Tacuarembó & 9,2 & 11,2 \\
\hline Comargen & 5,8 & 8,9 & La Caballada & 6,7 & 9,8 & La Caballada & 5,2 & 7,6 & Las Piedras & 10,0 & 10,2 \\
\hline Total 4 mayores & $33 \%$ & $55 \%$ & Total 4 mayores & $31 \%$ & $46 \%$ & Total 4 mayores & $32 \%$ & $40 \%$ & Total 4 mayores & $38 \%$ & $51 \%$ \\
\hline La Caballada & 4,8 & 8,9 & Comargen & 7,5 & 9,5 & $\begin{array}{l}\text { Cruz del Sur y } \\
\text { Colonia }\end{array}$ & 7,1 & 6,3 & Pul & 5,8 & 9,3 \\
\hline $\begin{array}{l}\text { G. Florida y } \\
\text { Canelones }\end{array}$ & 5,1 & 6,1 & EFCSA y Colonia & 6,1 & 8,7 & Las Piedras & 4,9 & 5,2 & Pando y Colonia & 5,9 & 7,6 \\
\hline Santos Lugares & 5,6 & 5,6 & Canelones & 5,1 & 7,4 & Industrial Pando & 5,1 & 4,9 & Elbio P. R. & 6,4 & 7,3 \\
\hline Morena y Canto & 4,7 & 3,4 & $\begin{array}{l}\text { Cruz del Sur } \\
\text { y Elbio }\end{array}$ & 4,4 & 2,9 & $\begin{array}{l}\text { Montes y } \\
\text { Codadesa }\end{array}$ & 4,0 & 3,4 & Sirsil y Clay & 5,6 & 2,2 \\
\hline Total 8 mayores & $53 \%$ & $79 \%$ & Total 8 mayores & $50 \%$ & $74 \%$ & Total 8 mayores & $53 \%$ & $60 \%$ & Total 8 mayores & $62 \%$ & $78 \%$ \\
\hline$\%$ de extranjeros & 0 & 0 & $\%$ de extranjeros & 0 & 0 & $\%$ de extranjeros & 0 & 0 & $\%$ de extranjeros & $8 \%$ & $24 \%$ \\
\hline
\end{tabular}

Más allá de cambios en el lugar que ocupan estos frigoríficos, su permanencia en el top 8 se verifica durante todo el período de estudio (tabla 6). Desde inicios de los noventa, no obstante, nuevas plantas adquieren relevancia y se suman al selecto grupo. Uno de ellos es el Frigorífico Pul, que
Nota: el nivel de faena corresponde a faena bovina y el de exportación al valor de exportaciones cárnicas.

Fuente: elaboración propia a partir de los Anuarios Estadísticos del INAC. 
Tabla 6. Nivel de concentración (según nivel de faena y valor exportado) por planta de faena y por firma* $(\%)$ inició sus operaciones en 1991. Otro es el Frigorífico Pando, que incursionó en el mercado de exportación en 1992. Por último, el Frigorífico Breeders \& Packers Uruguay (BPU), que se instaló en el 2010.

La información de las tablas 5 y 6, además de permitir la identificación de los actores más relevantes en la IF, aporta algunas "fotos" sobre qué tan concentrado se encuentra el sector. “La película completa” se infiere a partir de la figura 1, en donde se muestra el índice de entropía (IE), calculado según participación de la planta (y de la firma) en la faena bovina y en el valor de las exportaciones cárnicas.

\begin{tabular}{|c|c|c|c|c|c|c|c|c|c|c|c|}
\hline \multicolumn{3}{|c|}{$2000^{1}$} & \multicolumn{3}{|c|}{$2005^{2}$} & \multicolumn{3}{|c|}{$2010^{3}$} & \multicolumn{3}{|c|}{$2015^{4}$} \\
\hline Frigorífico & Faena & Exp. & Frigorífico & Faena & Exp. & Frigorífico & Faena & Exp. & Frigorífico & Faena & Exp. \\
\hline Pul & 10,0 & 12,1 & Las Piedras & 9,5 & 10,1 & Pando y Colonia & 5,5 & 8,6 & BPU & 7,5 & 9,2 \\
\hline Canelones & 9,9 & 11,6 & Colonia & 8,7 & 9,5 & Las Piedras & 7,4 & 8,5 & Tacuarembó & 6,9 & 8,5 \\
\hline San Jacinto & 9,1 & 11,2 & San Jacinto & 8,6 & 9,4 & Tacuarembó & 7,9 & 7,7 & Pul & 7,0 & 8,3 \\
\hline Tacuarembó & 8,9 & 9,5 & Tacuarembó & 8,4 & 8,7 & San Jacinto & 6,4 & 7,6 & Las Piedras & 6,6 & 7,3 \\
\hline Total 4 mayores & $38 \%$ & $44 \%$ & Total 4 mayores & $35 \%$ & $38 \%$ & Total 4 mayores & $\begin{array}{l}29 \% \\
43 \%\end{array}$ & $\begin{array}{l}32 \% \\
49 \%\end{array}$ & Total 4 mayores & $\begin{array}{l}28 \% \\
49 \%\end{array}$ & $\begin{array}{l}34 \% \\
54 \%\end{array}$ \\
\hline Las Piedras & 10,1 & 8,7 & Canelones & 7,5 & 8,4 & Pul & 6,6 & 6,4 & Canelones & 7 & 6,6 \\
\hline Carrasco & 7,1 & 8,6 & Carrasco & 8,4 & 8,3 & Carrasco & 6,5 & 6,2 & San Jacinto & 5,5 & 6,0 \\
\hline Colonia & 5,0 & 7,2 & Pul & 8,6 & 8,2 & Canelones & 6,6 & 5,8 & Pando y Colonia & 5,1 & 5,3 \\
\hline $\begin{array}{l}\text { Pando y Elbio P. } \\
\text { Rodríguez }\end{array}$ & 6,8 & 4,8 & Pando & 6,7 & 6,7 & $\begin{array}{l}\text { Inaler (ex. Elbio P. } \\
\text { Rodríguez) }\end{array}$ & 5,4 & 5,4 & $\begin{array}{l}\text { La Caballada y } \\
\text { Carrasco }\end{array}$ & 4,9 & 5,0 \\
\hline Total 8 mayores & $\begin{array}{l}66 \% \\
76 \%\end{array}$ & $\begin{array}{l}74 \% \\
84 \%\end{array}$ & Total 8 mayores & $\begin{array}{l}66 \% \\
76 \%\end{array}$ & $\begin{array}{l}69 \% \\
74 \%\end{array}$ & Total 8 mayores & $\begin{array}{l}52 \% \\
70 \%\end{array}$ & $\begin{array}{l}56 \% \\
74 \%\end{array}$ & Total 8 mayores & $\begin{array}{l}50 \% \\
71 \%\end{array}$ & $\begin{array}{l}57 \% \\
75 \%\end{array}$ \\
\hline$\%$ de extranjeros & $23 \%$ & $30 \%$ & $\begin{array}{l}\text { \% de extran- } \\
\text { jeros }\end{array}$ & $33 \%$ & $36 \%$ & $\begin{array}{c}\% \text { de } \\
\text { extranjeros }\end{array}$ & $39 \%$ & $48 \%$ & $\begin{array}{c}\% \text { de extran- } \\
\text { jeros }\end{array}$ & $39 \%$ & $49 \%$ \\
\hline
\end{tabular}

Notas: *Las cifras subrayadas corresponden a la concentración según firma. 'Carrasco, Las Moras y Elbio P. Rodríguez del grupo CATER; ${ }^{2}$ Carrasco, Las Moras y Elbio P. Rodríguez del grupo CATER; ${ }^{3}$ Carrasco y Las Moras del grupo CATER; Colonia, Tacuarembó e Inaler (ex. Elbio P. Rodríguez) del grupo MARFRIG; ${ }^{4}$ Colonia y Tacuarembó del grupo MARFRIG; Pul y Carrasco del grupo MINERVA FOODS.

Fuente: elaboración propia a partir de los Anuarios Estadísticos del INAC. 


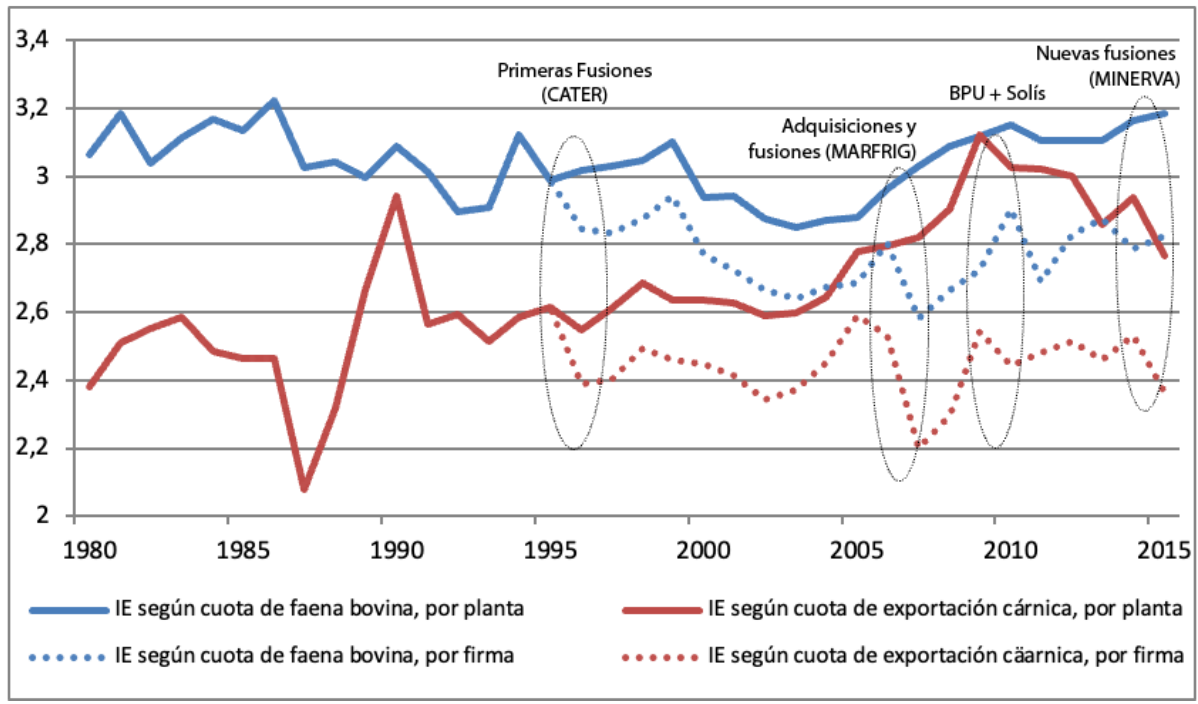

De la figura 1 se infiere lo siguiente:

i. Disminuyó la brecha entre el nivel de concentración según valor exportado y según cantidad faenada. Desde finales de la década del 80 la brecha disminuye por un doble efecto: una tendencia creciente en el nivel de concentración según la cantidad faenada y una menor concentración según valor exportado. La disminución de la brecha tiene lógica si se considera el mayor peso que adquirió el mercado exportador en detrimento del interno. Probablemente, la marcada reorientación exportadora de la IF permitió mayores incrementos del nivel de faena en aquellas plantas de mayor tamaño y con mejores condiciones para redirigir sus productos a los nuevos mercados. De hecho, un factor distintivo durante la última década bajo estudio es que las principales plantas frigoríficas que lideran las exportaciones son a su vez las que se imponen en el doméstico. ${ }^{6}$ La convergencia del nivel de concentración según faena y exportación comienza a revertirse hacia finales del período de estudio, cuando la concentración del segmento exportador vuelve a aumentar.

ii. Tomando como unidad la planta, se constata una disminución de la concentración de la IF menos significativa para el promedio de la industria que para el segmento exportador.

iii. Tomando como unidad la firma, es decir, midiendo la concentra-
Figura 1. Índice de entropía (según faena y exportación) por planta y por firma

Nota: el IE mide el grado de entropía existente en las cuotas de mercado $\mathrm{IE}=\sum \mathrm{si} \mid \mathrm{n}(1 / \mathrm{si})$, si = cuota de mercado de la planta i (o firma i) en la faena o la exportación total. Cuanto mayor el IE, mayor entropía; es decir, mayor competencia en el mercado y por tanto menor concentración

Fuente: elaboración propia con base en los Anuarios Estadísticos del INAC. 
ción de la industria frigorífica según propiedad del capital accionario, el sector se encuentra más concentrado de acuerdo al nivel faenado. En lo que refiere al mercado de exportación, a 2015 este se encontraba tan concentrado como en 1980.

iv. La diferencia entre ambos resultados (ii y iii) se debe al proceso de adquisiciones y fusiones registrado desde la segunda mitad de los noventa, que implica la presencia de varias plantas de faena bajo propiedad de un mismo grupo accionario.

v. En 1996, cuando se producen las primeras fusiones, ${ }^{7}$ aumenta el nivel de concentración; tendencia que se mantiene hasta 2002/2003 tanto en el mercado exportador como en la industria en su conjunto. A partir de entonces hay una tendencia a la baja en el nivel de concentración según cantidad faenada, así como una mayor concentración del mercado exportador. También se aprecia una mayor oscilación en los niveles de entropía, en paralelo a la intensificación de adquisiciones y fusiones. El incremento pronunciado de la concentración entre 2005 y 2007 se corresponde con un intenso proceso de adquisiciones y fusiones, protagonizado por la firma brasileña MARFRIG. ${ }^{8}$ A partir del 2010, el aumento en la concentración se debe al comienzo de operaciones del $\mathrm{BPU}^{9}$, el cual ya mantenía operaciones en el Solís, y desde 2014 se corresponde con nuevas fusiones a cargo de Minerva Foods. ${ }^{10}$

El proceso de adquisiciones y fusiones fue promovido por el ingreso de Inversión Extranjera Directa (IED) al sector. En la figura 2 se identifica una primera oleada entre 1994 y 2005, cuyo origen de capital es variado, y cuya Arbiza, bajo CATER GROUP, de capitales nacionales, propiedad de Costa Valverde y Misa Martínez (Geymonat, 2019, p. 160). A partir de 2006, Elbio P. Rodríguez es adquirido por MARFRIG. CATER sigue operando, conformado por Carrasco y Las Moras, hasta el 2013, cuando el Frigorífico Carrasco es adquirido por MINERVA FOODS.

8 MARFRIG GROUP, de origen brasileño, inició sus operaciones en 1986. Marfrig Alimentos S.A. opera en América del Sur y EE. UU., y figura segunda en el ranking mundial de ventas de carne bovina. En Uruguay, adquirió los frigoríficos Tacuarembó y Elbio P. Rodríguez en 2006, y La Caballada y Colonia en 2007. Además cuenta con una planta que produce corned beef en Fray Bentos desde 2008.

9 Breeders \& Pakers Meat Uruguay (BPU) se instaló en 2010. Su dueño, Terry Johnson, de la firma inglesa Breeders \& Pakers, había adquirido acciones en Carne Hereford del Uruguay en 2006, el 51 $\%$ del capital accionario del Frigorífico Solís en 2007 y tenía acciones en Carne Aberdeen Angus Uruguay S.A. En 2012, el Solís vuelve a ser propiedad de capitales nacionales. En 2017 BPU es vendido a NH Foods (Nippon Meat Packers), firma japonesa líder en su país.

10 MINERVA FOODS es una firma de origen brasileño, en actividad desde 1992, especializada en la producción y comercialización de carne. Esta opera en varios países de América del Sur. En Uruguay adquirió el Frigorífico PUL en 2011, La Caballada en 2014 y Canelones en 2017. 
modalidad predominante es la adquisición de plantas ya operativas. La segunda oleada se origina en 2006 , tiene predominio brasileño y como estrategia predominante utiliza las fusiones, además de las adquisiciones.

Figura 2. IED en la IF

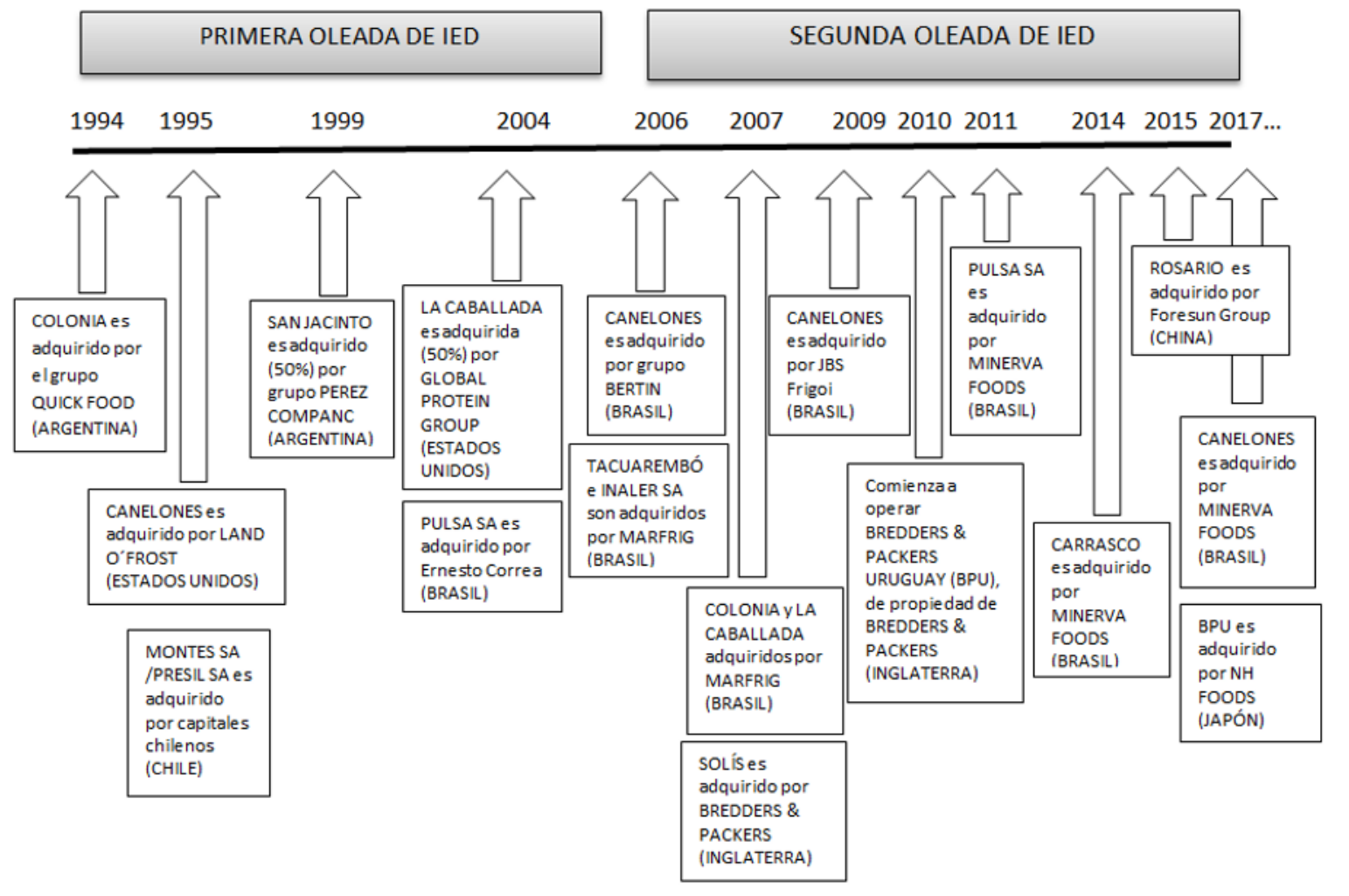

El proceso de IED explica que mientras en 1995 la participación del capital extranjero en la faena total era de $8 \%$ y en el valor exportado de $24 \%$, Fuente: elaboración propia con base en Bittencourt et al. (2011) y en 2015 esos porcentajes ascienden a 39 y $49 \%$, respectivamente (tabla 6). Estas cifras son aún mayores si se considera la concentración según grupo económico. A finales del período, las primeras ocho empresas concentran el $70 \%$ de la faena y el $75 \%$ del total exportado, estando en manos de capitales extranjeros el 58 y $62 \%$, respectivamente.

La trasnacionalización de la IF se enmarca en un contexto de transformaciones a nivel global que ha promovido nuevas estrategias empresariales, como la adquisición de plantas en países con buenas condiciones de producción, el establecimiento de redes de distribución y marcas con grandes retailers y alianzas comerciales con industriales locales en los países destino (Bisang et al., 2008). El ingreso de IED a la IF uruguaya se origina, a su vez, tras la creación del MERCOSUR. Durante los noventa, los primeros capitales 
extranjeros fueron argentinos, Quickfood S.A. ${ }^{11}$ y Pérez Companc, ${ }^{12}$ y desde comienzos del 2000 los capitales brasileños son los de mayor expansión.

Más allá de la cercanía geográfica, la IED en la IF uruguaya se explica por ciertas fortalezas a nivel país y por factores de atracción propios del sector (Bittencourt et al., 2011). A nivel país, los autores destacan la seguridad jurídica, la estabilidad macroeconómica y política, la disponibilidad de mano de obra calificada y el régimen de promoción de inversiones. Respecto al sector, señalan la calidad de la materia prima, el estatus sanitario, la trazabilidad y el acceso a los principales mercados con cuotas preferenciales.

Es pertinente preguntarse el porqué de las ventas de las plantas prósperas ubicadas en Uruguay. Bisang et al. (2008), aludiendo a la venta de empresas argentinas a inversores internacionales, sostienen que el mayor acceso a financiamiento externo de las empresas trasnacionales (ET) posibilita la inversión en procesos de expansión y desarrollo estratégico, y dificulta la competitividad de las empresas nacionales. Este factor podría haber operado en Uruguay. Cabe notar que tras la crisis financiera de 2002 la política crediticia, que hasta entonces había estado fuertemente centralizada en el Banco República, se discontinuó y la IF pasó a operar con recursos propios (Alfaro \& Olivera, 2009). Estos factores, no obstante, constituyen posibles hipótesis explicativas, y requieren mayor análisis para su cotejo.

En la tabla 7 se identifican las plantas que han liderado las dos reconversiones y en la figura 3 se presenta su localización y la propiedad actual de su capital accionario según nacionalidad. La importancia del grupo de frigoríficos líderes se aprecia en la figura 4.

11 Quickfood S.A. es una de las principales empresas alimenticias argentinas. En 2007 fue adquirida por la firma brasileña MARFRIG, en 2011 se fusionó con Argentine Breeders \& Packers S.A., Mirab S.A. y Best Beef S.A. En 2011, BRF de capitales brasileños adquirió la mayoría accionaria de Quickfood S.A., aunque el negocio frigorífico volvió a manos de MARFIRG en 2018 (http://www. evaluadora.com/ar/usr/archivos/935_Quickfood.pdf).

12 La firma Pérez Companc surgió en 1946, centrada en el sector energético, y en 2000 incursionó en alimentos. Actualmente tiene el $100 \%$ de las acciones del Frigorífico San Jacinto (Sala, 2009, pp. 112-118). 


\begin{tabular}{|c|c|c|c|c|c|}
\hline \multirow{2}{*}{$\begin{array}{c}\text { Top } 13 \\
\text { frigoríficos }\end{array}$} & \multirow{2}{*}{$\begin{array}{l}\text { Inicio } \\
\text { activi- } \\
\text { dad }\end{array}$} & \multicolumn{2}{|c|}{ Propiedad del capital accionario } & \multicolumn{2}{|c|}{$\begin{array}{c}\text { Capacidad insta- } \\
\text { lada } \\
\text { (reses/día) }\end{array}$} \\
\hline & & $\begin{array}{l}\text { Origen del } \\
\text { capital }\end{array}$ & Cambios de propiedad & Inicio & Actual \\
\hline Carrasco & 1962 & Nacional & $\begin{array}{l}\text { 1996. CATER GROUP (UY) } \\
\text { 2014. MINERVA FOODS (BR) }\end{array}$ & 600 & 1200 \\
\hline Pando & 1955 & $\begin{array}{c}\text { Nacional } \\
\text { (ONTILCOR S.A.) }\end{array}$ & & 200 & 1000 \\
\hline Tacuarembó & 1963 & Nacional & 2006. MARFRIG (BR) & 320 & 1100 \\
\hline Colonia & 1965 & Nacional & $\begin{array}{l}\text { 1994. QUICK FOOD (ARG) } \\
\text { 2007. MARFRIG (BR) }\end{array}$ & 200 & 1100 \\
\hline La Caballada & 1964 & $\begin{array}{c}\text { Nacional } \\
\text { (CYBARÁN S.A.) }\end{array}$ & $\begin{array}{l}\text { 1995-2003: inactiva } \\
\text { 2004. CLEDINOR S.A. (UY) + Grupo } \\
\text { PRESTCOTT INT. (EE. UU. - } 50 \text { \%) } \\
\text { 2007. MARFRIG (BR) }\end{array}$ & 220 & 800 \\
\hline San Jacinto & 1966 & $\begin{array}{l}\text { Nacional } \\
\text { (NIREA S.A.) }\end{array}$ & $\begin{array}{l}\text { 1999. PÉREZ COMPANC (ARG - } 51 \% \text { ) } \\
\text { 2019. PÉREZ COMPANC ( } 100 \%)\end{array}$ & 200 & 1000 \\
\hline Canelones & 1964 & Nacional & $\begin{array}{l}\text { 1995. LAND O’FROST (EE. UU.) } \\
\text { 2006. GRUPO BERTIN (BR) } \\
\text { 2009. JBS FRIGOI (BR) adquiere } \\
\text { BERTÍN } \\
\text { 2017. MINERVA FOODS (BR) }\end{array}$ & 320 & 800 \\
\hline Las Piedras & 1978 & Nacional & Nacional & 400 & 1000 \\
\hline Las Moras & 1978 & $\begin{array}{c}\text { Nacional } \\
\text { (CHIADEL S.A.) }\end{array}$ & $\begin{array}{l}\text { 1996. CATER GROUP (UY) } \\
\text { 2006. Nacional }\end{array}$ & 180 & 600 \\
\hline $\begin{array}{c}\text { Elbio P. } \\
\text { Rodríguez / } \\
\text { Inaler S.A. }\end{array}$ & 1980 & Nacional & $\begin{array}{l}\text { 1996. CATER GROUP (UY) } \\
\text { 2006. MARFRIG (BR) }\end{array}$ & 240 & 700 \\
\hline Pul & 1991 & $\begin{array}{l}\text { Nacional } \\
\text { (PUL S.R.L.) }\end{array}$ & $\begin{array}{l}\text { 2000. Ernesto Correa (BR) } \\
\text { 2011. MINERVA FOODS (BR) }\end{array}$ & - & 1400 \\
\hline Solís & 1995 & $\begin{array}{c}\text { Nacional } \\
\text { (ERSINAL S.A.) }\end{array}$ & $\begin{array}{l}\text { 2007. BPU (ING - } 51 \% \text { ) } \\
\text { 2012. Nacional }\end{array}$ & - & 450 \\
\hline BPU & 2010 & $\begin{array}{c}\text { Inglés } \\
\text { (BREDDERS \& } \\
\text { PACKERS) }\end{array}$ & 2017. NH F00DS (JAP) & $\begin{array}{c}1200 \\
(2 \\
\text { turnos })\end{array}$ & $\begin{array}{c}2000 \\
\text { (2 turnos) }\end{array}$ \\
\hline
\end{tabular}

Tabla 7. Principales características de las plantas líderes 
Figura 3. Localización y

capital accionario de las plantas líderes

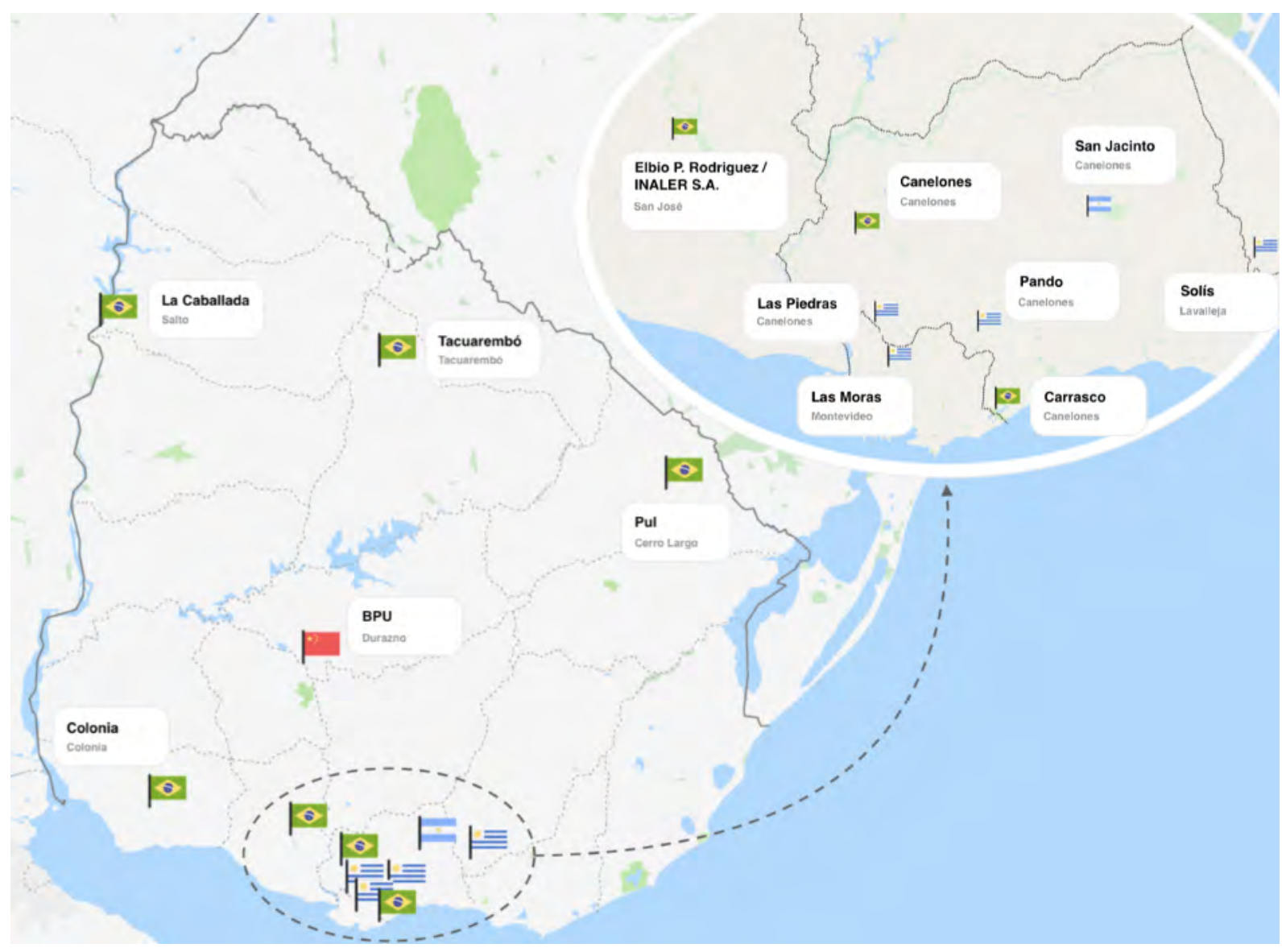

Fuente: elaboración propia (mapa obtenido de https://www.google. com/maps).

Figura 4. Participación de los Top 13 en la faena bovina y la exportación cárnica

Fuente: elaboración propia a partir de los Anuarios Estadísticos del INAC.

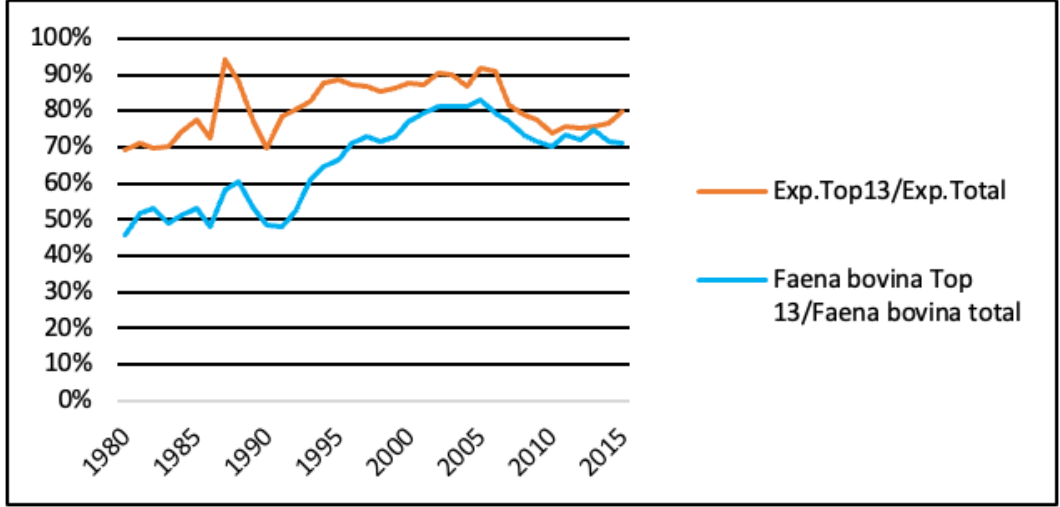




\section{EL DESEMPEÑO PRODUCTIVO DE LA IF}

Con base en las encuestas industriales trimestrales realizadas por el INE, en la figura 5 se muestra la evolución del índice de volumen físico (IVF), el Índice de horas de trabajo requeridas (IHT) y el índice de productividad aparente (IPA) de la industria frigorífica ${ }^{13}$.

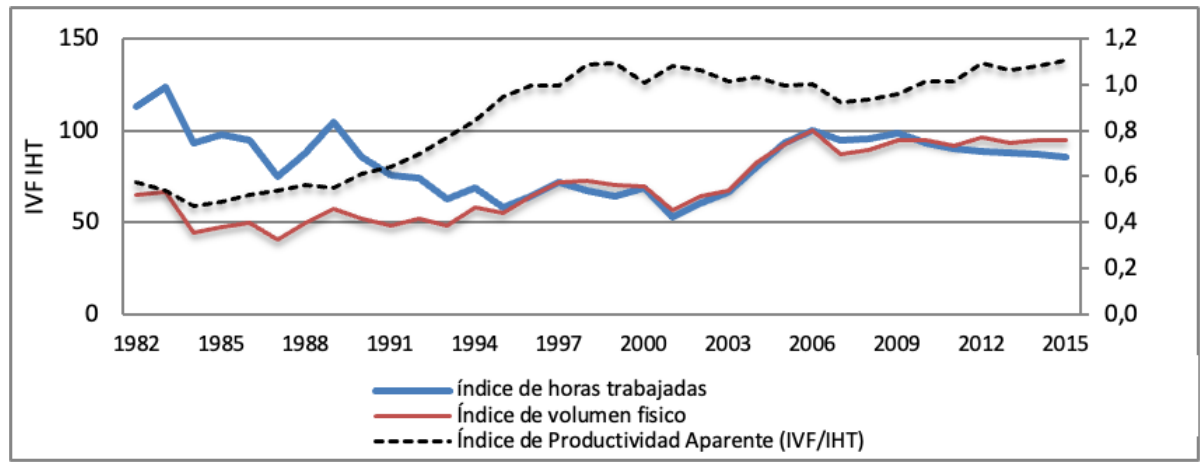

Se aprecia un incremento del nivel de actividad de la IF, en especial desde finales de la década del ochenta, el cual se encuentra determinado tanto por factores de demanda como por condicionantes en la oferta de la materia prima. Entre los primeros, el magro dinamismo de la IF durante casi toda la década del ochenta se vincula al tipo de inserción externa. Durante esos años las exportaciones se encontraban fuertemente dependientes de la región, en particular de Brasil, lo que le imprimía a la actividad una dinámica excesivamente oscilante. Si bien algunos países europeos habían adquirido mayor significancia como importadores, sus políticas fuertemente proteccionistas y las elevadas exigencias en materia higiénico-sanitarias dejaban fuera a gran parte de las plantas que conformaban la IF en aquella época. En lo que se refiere a los factores de oferta, aún persistían varios de los obstáculos señalados como principales causas del estancamiento ganadero que sobrevino a las dos primeras décadas del siglo XX.

Por el contrario, el período de mayor crecimiento del IVF (1994-2005) coincide con una fase expansiva de las exportaciones, asociada al acceso al circuito no aftósico, una menor dependencia de la demanda de los países de la región y un paulatino corrimiento hacia mercados más estables y con preferencias asociadas al consumo de cortes de mayor calidad. Por otro
Figura 5. IPA, IVF e IHT de la IF (promedio anual $2006=$ 100)

Fuente: elaboración propia con datos de la Unidad de Métodos y Acceso a Datos de la FCS, según el INE.

13 Se tomó la rama 1511, según la Clasificación Industrial Internacional Uniforme (CIIU), Revisión 3:"Matanza de ganado (vacuno, ovino, equino y porcino) y de otros animales. Preparación y conservación de carnes. Extracción y refinación de manteca de cerdo y otras grasas comestibles". 
lado, y en lo que hace a los factores de oferta, la menor variación intra e interanual de la faena y la mejora en las condiciones técnicas de la producción de carne posibilitaron una mayor regularidad en el abastecimiento de la materia prima y mejoras en la calidad.

Ahora bien, el aumento del IVF no respondió solo a cambios en el contexto internacional y a estímulos provenientes de la fase primaria. Como muestra la figura 5, el incremento del volumen físico desde finales de la década de 1980 fue acompañado de un aumento en la productividad del trabajo en la propia industria. Los cambios en el IPA están asociados a las variaciones registradas en el nivel de empleo, el cual puede variar ya sea por cambios en el nivel de actividad o por la introducción de innovaciones tecnológicas y organizacionales (eventualmente, ahorradoras de mano de obra).

De acuerdo con la figura 5, el IPA se incrementó de forma sostenida entre 1984 y 1999, período en que se registró una fuerte caída del nivel de empleo. Mientras que durante los primeros años dicha caída se correspondió con el menor nivel de actividad de la IF, a partir de 1987 y hasta mediados del noventa coincidió con un aumento de la producción. La pérdida de empleo se debió a los cambios organizacionales y técnicos implementados durante esos años (Espino \& Salazar, 2000). Desde entonces y hasta 2007, la evolución de la producción y el empleo se movieron al unísono. Por consiguiente, el IPA — si bien con tendencia decreciente - se mantuvo relativamente estable. Este hecho podría estar vinculado al mayor peso que adquirieron los cortes deshuesados en la composición total de productos ofrecidos por la IF. La actividad de desosado es más intensiva en mano de obra, pudiendo haber actuado como efecto contrapuesto a la incorporación de tecnología ahorradora de mano de obra. A partir de 2007 y hasta 2015, el nivel de empleo volvió a mostrar una tendencia a la baja. Esta, no obstante, fue de menor significación a la registrada durante la primera reconversión y no se correspondió con caídas en el nivel de actividad. El incremento del IPA experimentado durante esos años, probablemente esté asociado a la creciente automatización de procesos - aún en curso-que viene registrando la IF.

En efecto, la introducción de innovaciones al sector ha sido un componente central en la dinámica de la productividad del trabajo, así como en la evolución creciente del IVF desde finales de la década de los ochenta. Como se mencionó en el apartado anterior, durante la primera reconversión se introdujeron procesos de racionalización industrial, se ajustó la capacidad 
técnica entre las fases de procesamiento y se incorporaron tecnologías ahorradoras de mano de obra. Estos factores explican en gran medida por qué la significativa reducción del nivel de empleo no redundó en una caída proporcional del IVF hasta mediados de la década del noventa.

La conducta innovadora de la industria cárnica durante la segunda reconversión es aproximada a partir de las Encuestas de Actividades de Innovación (EAI) de la Industria manufacturera (IM), realizadas por la ANII. A partir de las EAI 1998-2000 y 2004-2006, ${ }^{14}$ mientras que el nivel de inversión de las empresas innovativas ${ }^{15}$ en las ramas de alimentos, tabaco y bebidas (IABT) se mantuvo prácticamente estable y la inversión registrada al 2006 para el total manufacturero fue $9 \%$ mayor que la del 2000, la inversión de la rama 1511 al 2006 más que duplicó la registrada en el 2000 (tabla 8).

\begin{tabular}{|c|c|c|c|c|c|}
\hline $\begin{array}{c}\text { Inversión actividades } \\
\text { de innovación } \\
\text { (miles USD) }\end{array}$ & Rama 1511 & IABT & IM & $\begin{array}{c}\text { 1511/IABT } \\
\text { (\%) }\end{array}$ & $\begin{array}{c}\text { 1511/IM } \\
\text { (\%) }\end{array}$ \\
\hline 2000 & 10.700 & 73.118 & 203.898 & 15 & 5 \\
\hline 2006 & 23.393 & 73.453 & 222.041 & 32 & 11 \\
\hline
\end{tabular}

En la tabla 9 se aprecia que el conjunto de empresas innovativas de la rama 1511 está conformado por empresas grandes. Estas concentran $76 \%$ de las ventas totales y $67 \%$ de los ocupados en la rama, a pesar de representar $48 \%$ del total de empresas. En el mismo sentido, se observa que las empresas innovativas son las que tienen mayor participación en el mercado de exportación, concentrando 78 \% del valor total exportado en 2006.

\begin{tabular}{|c|c|c|c|}
\hline Año 2006 & Total & Innovativas (\%) & No innovativas (\%) \\
\hline N. ${ }^{\circ}$ de empresas & 65 & 48 & 52 \\
\hline Ventas (miles USD) & 1.518 & 76 & 24 \\
\hline Exportaciones (miles USD) & 1.052 & 78 & 22 \\
\hline N. ${ }^{\circ}$ de ocupados & 13.032 & 67 & 33 \\
\hline
\end{tabular}

Tabla 9. Principales indicadores económicos según conducta innovadora de la rama 1511

Fuente: elaboración propia con base en la EAI 2004-2006.
Tabla 8. Inversión en actividades de innovación de la rama 1511 , la IABT y la IM (2000-2006)

Fuente: elaboración propia con base en las EAI 1998-2000 y la EAI 2004-2006 y a ANII (2015).

\footnotetext{
14 No se encuentran disponibles los microdatos de la EAl a 4 dígitos para el período 2001-2003. Las EAI son representativas a 2 dígitos (y no a 4 dígitos), pero las empresas habilitadas a nivel nacional que conforman la IF cumplen, mayoritariamente, con los criterios considerados para ser de inclusión forzosa en la muestra.

15 Se denomina empresa innovativa a la unidad económica que realizó alguna actividad de innovación. Se consideran actividades de innovación a las acciones llevadas a cabo por una empresa para generar cambios, adelantos o mejoras que incidan positivamente en su desempeño.
} 
Tabla 10. Inversión en actividades de innovación de la rama 1011 , la IABT y la IM (2009-2015)

Fuente: elaboración propia a partir de las EAI 2007-2009, EAl 20102012 y EAI2013-2015, ANII (2015) y la Infografía sobre los resultados de la EAI 2013-2015 (ANII, n.d.).

Tabla 11. Participación en las ventas y ocupados totales según conducta innovadora
Los datos de las encuestas correspondientes a los períodos 2007-2009, 2010-2012 y 2013-2015 dan cuenta de la importancia de la inversión realizada por las empresas innovativas pertenecientes a la IF, aproximada a través de la Rama $1011^{16}$ (tabla 10). Se destaca el monto invertido en 2014 que explicó un tercio del total invertido por la IM, y se debió a la inversión en bienes de capital que realizó MARFRIG en su planta ubicada en Colonia.

\begin{tabular}{|c|c|c|c|c|c|}
\hline $\begin{array}{c}\text { Inversión actividades } \\
\text { de innovación }\end{array}$ & $\begin{array}{c}\text { Rama 1011 } \\
\text { (miles USD) }\end{array}$ & $\begin{array}{c}\text { IABT } \\
\text { (miles USD) }\end{array}$ & $\begin{array}{c}\text { IM } \\
\text { (miles USD) }\end{array}$ & $\begin{array}{c}\text { 1011/IABT } \\
\text { (\%) }\end{array}$ & 1011/IM (\%) \\
\hline 2009 & 24.950 & 98.985 & 436.714 & 25 & 6 \\
\hline 2010 & 9.331 & 74.192 & 316.320 & 13 & 3 \\
\hline 2011 & 5.868 & 49.025 & 260.459 & 12 & 2 \\
\hline 2012 & 11.086 & 86.796 & 255.816 & 13 & 4 \\
\hline 2013 & 2.355 & 160.064 & 388.392 & 1 & 1 \\
\hline 2014 & 148.567 & 277.502 & 442.581 & 54 & 34 \\
\hline 2015 & 7.959 & 118.773 & 235.234 & 7 & 3 \\
\hline
\end{tabular}

Al examinar el perfil de las empresas innovativas (tabla 11), se constata que las empresas de mayor tamaño tienen mayor representación en el conjunto de las innovativas. Lo mismo es inferido al observar el perfil del conjunto de empresas innovativas según su participación en el total de exportaciones de la rama (tabla 12).

\begin{tabular}{|c|c|c|c|c|c|c|c|c|c|}
\hline $\begin{array}{c}\text { Rama } \\
1011\end{array}$ & $\begin{array}{c}\text { N. }{ }^{\circ} \\
\text { empresas }\end{array}$ & $\begin{array}{l}\text { Innov. } \\
(\%)\end{array}$ & $\begin{array}{c}\text { No innov. } \\
(\%)\end{array}$ & $\begin{array}{l}\text { Ventas } \\
\text { (mill USD) }\end{array}$ & $\begin{array}{c}\text { Innov. } \\
(\%)\end{array}$ & $\begin{array}{c}\text { No innov. } \\
(\%)\end{array}$ & N. ${ }^{\circ}$ ocupados & $\begin{array}{c}\text { Innov. } \\
(\%)\end{array}$ & $\begin{array}{c}\text { No innov. } \\
(\%)\end{array}$ \\
\hline 2010 & 37 & 51 & 18 & 1.933 & 70 & 30 & 12.729 & 68 & 32 \\
\hline 2011 & 37 & 51 & 18 & 2.303 & 73 & 27 & 12.400 & 67 & 33 \\
\hline 2012 & 37 & 51 & 18 & 2.484 & 69 & 31 & 12.731 & 68 & 32 \\
\hline 2013 & 41 & 54 & 19 & 2.315 & 69 & 31 & 12.687 & 67 & 33 \\
\hline 2014 & 41 & 54 & 19 & 2.506 & 64 & 36 & 12.756 & 67 & 33 \\
\hline 2015 & 41 & 54 & 19 & 2.973 & 73 & 27 & 13.243 & 67 & 33 \\
\hline
\end{tabular}

Fuente: elaboración propia con base en las EAI 2010-2012 y EAI 2013-2015.

16 En 2008 se aprobó la CIIU, Revisión 4. La rama 1511 de la Revisión 3 equivale a las ramas: 1011 (Matanza de animales y otros animales (excepto aves), conservación y preparación de sus carnes); 1012 (Elaboración de fiambres y chacinados); 1014 (Matanza, preparación y conservación de pollos y gallinas); y 1019 (Matanza, procesamiento y conservación de carne de ñandúes y otras aves n.c.p.). 


\begin{tabular}{|c|c|c|c|c|c|c|}
\hline Rama 1011 & $\begin{array}{c}\text { N. }{ }^{\circ} \text { de } \\
\text { empresas }\end{array}$ & Innov. (\%) & No innov. (\%) & $\begin{array}{c}\text { Exportaciones } \\
\text { (mill USD) }\end{array}$ & Innov. (\%) & No innov. (\%) \\
\hline 2010 & 37 & 51 & 18 & 1.255 & 70 & 30 \\
\hline 2011 & 37 & 51 & 18 & 1.464 & 73 & 27 \\
\hline 2012 & 37 & 51 & 18 & 1.589 & 69 & 31 \\
\hline 2013 & 41 & 54 & 19 & 1.406 & 69 & 31 \\
\hline 2014 & 41 & 54 & 19 & 1.558 & 64 & 36 \\
\hline 2015 & 41 & 54 & 19 & 1.915 & 73 & 27 \\
\hline
\end{tabular}

Tabla 12. Participación en las exportaciones, según conducta innovadora

Fuente: elaboración propia con base en las EAl 2010-2012 y EAl 2013-2015.

Otro aspecto a indagar en el perfil de las empresas es la conducta innovadora según el origen del capital (tabla 13). Se observa una mayor presencia de conducta innovadora entre las empresas con participación de capital extranjero. Mientras que, en promedio, el $70 \%$ de las ET realizan al menos una actividad de innovación entre 2007 y 2015, esa cifra se reduce al 50 \% para el conjunto de empresas nacionales. Este último resultado no es independiente del que surge al observar la conducta innovadora de las empresas, según tamaño y propensión exportadora. Además, vale notar que las empresas de capitales extranjeros se encuentran entre las plantas de mayor tamaño y tienen una orientación exportadora.

\begin{tabular}{|c|c|c|}
\hline Rama 1011 (\% innov.) & Nacionales & Extranjeras \\
\hline $2007-2009$ & $48 \%$ & $70 \%$ \\
\hline $2010-2012$ & $52 \%$ & $60 \%$ \\
\hline $2013-2015$ & $57 \%$ & $82 \%$ \\
\hline
\end{tabular}

Tabla 13. Conducta innovadora de las empresas según origen del capital accionario

Fuente: elaboración propia con base en las EAl 2007-2009, EAl 2010-2012 y EAI 2013-2015.

Es interesante examinar en qué innovan las empresas innovativas durante el subperíodo considerado (2007-2015). De acuerdo con la tabla 14, estas han realizado mayoritariamente innovaciones en procesos.

\begin{tabular}{|c|c|c|c|c|}
\hline Tipo de innovación & Producto (\%) & Proceso (\%) & Organización (\%) & Comercialización (\%) \\
\hline $2007-2009$ & 35 & 96 & 35 & 13 \\
\hline $2010-2012$ & 37 & 68 & 32 & 21 \\
\hline $2013-2015$ & 55 & 68 & 32 & 18 \\
\hline
\end{tabular}

Tabla 14. Tipo de innovaciones realizadas en la rama 1011

Fuente: elaboración propia con base en las EAl 2007-2009, EAI 2010-2012 y EAI 2013-2015.

Por último, la tabla 15 muestra que la gran mayoría de las empresas de la Rama 1011 cuenta con puntos de control de calidad, ha incorporado certificaciones en proceso y también, pero en menor grado, de productos. La inversión en actividades de innovación centradas en la calidad e inocuidad 
de los productos tiene importancia por ser condición necesaria del acceso a mercados más exigentes y por su potencial para aumentar el valor agregado, vía la incursión en nuevos productos o a través de atributos diferenciales. La creación de valor en este último caso se encuentra en los recursos intangibles añadidos durante el proceso de producción.

Tabla 15. Control de calidad, productos y procesos certificados

Fuente: elaboración propia con base en las EAI 2007-2009, EAI 2010-2012 y EAI 2013-2015.

\begin{tabular}{|c|c|c|c|c|}
\hline Rama 1011 & Total de empresas & $\begin{array}{c}\text { N. }{ }^{\circ} \text { de empresas } \\
\text { con puntos de } \\
\text { control de calidad }\end{array}$ & $\begin{array}{c}\text { N. }{ }^{\circ} \text { de empresas } \\
\text { con productos } \\
\text { certificados }\end{array}$ & $\begin{array}{c}\text { N. }{ }^{\circ} \text { de empresas } \\
\text { con procesos } \\
\text { certificados }\end{array}$ \\
\hline $2007-2009$ & 41 & 34 & 7 & 14 \\
\hline $2010-2012$ & 37 & 34 & 9 & 16 \\
\hline $2013-2015$ & 41 & s/d & s/d & s/d \\
\hline
\end{tabular}

\section{CONCLUSIONES}

Durante la década de 1980, la IF pasó a estar conformada por un número mayor de plantas de faena, de tamaño pequeño y medio, ancladas al sur del país y en propiedad de nacionales. Esta industria reconvertida abarcaba la nueva industria y las plantas que surgieron al influjo de las nuevas expectativas tras el auge liberalizador. A mediados de los noventa, otra reconfiguración comenzó a perfilarse y se extendió hasta finales del período de estudio. El origen del capital pasó a manos de extranjeros, mayoritariamente brasileños, y emergió el modelo multiplanta. Dado el tipo de incursión de la IED en el sector, principalmente bajo adquisiciones y fusiones, y no instalaciones, la industria cárnica resultante se conforma por el núcleo duro de plantas frigoríficas líderes que emergieron de la primera reconversión pero reconvertido. Esto es, con mayor capacidad instalada y sustantivas mejoras tecnológicas, y bajo otro capital accionario. A este grupo de plantas líderes se suman algunos otros establecimientos frigoríficos surgidos en los noventa y durante la última década de estudio, los cuales también en su mayoría han sido adquiridos por capitales extranjeros.

En lo que refiere al desempeño de la industria cárnica, se observa un incremento de la producción, en especial desde mediados de los 90 y hasta el 2006. El aumento de la capacidad instalada y (en menor grado) de la efectiva, así como la introducción de mejoras tecnológicas y organizacionales fuertemente centradas en la innovación de procesos, son factores que 
ayudan a explicar tal resultado. Respecto a la productividad de la mano de obra, dos tendencias contrapuestas han caracterizado la evolución del factor trabajo desde fines de los ochenta. Por un lado, la tendencia creciente a incorporar innovaciones tecnológicas ahorradoras de mano de obra y la tercerización de algunas actividades; por otro, el creciente peso de las actividades comprendidas dentro del desosado, más intensivas en mano de obra que las de la faena. Esto último se asocia a los cambios en la composición de la canasta exportadora, en especial a la creciente participación de partidas sin hueso en el total exportado. Durante la última década de estudio el nivel de empleo se redujo, pero a diferencia de la caída registrada durante los ochenta, este fue de menor significancia y no se correspondió con caídas en el nivel de actividad. La incorporación tecnológica y el proceso creciente de automatización de procesos explican el aumento de la productividad laboral de los últimos años. Hacia finales del período de estudio, el IPA de la IF se ubica en el entorno del $1 \%$, casi el doble al registrado a comienzos de la década del ochenta.

La introducción de innovaciones tecnológicas ha sido un componente central de la dinámica de la productividad laboral y del nivel de actividad de las plantas. Durante su primera reconversión, la IF introdujo procesos de racionalización industrial y nuevas tecnologías ahorradoras de mano de obra. Durante su segunda reconversión, los principales cambios fueron la mejora en la gestión de frío, innovaciones de proceso para garantizar la inocuidad y la introducción de las TIC en la cadena de procesamiento. Por último, cabe notar que el desarrollo tecnológico de la IF no ha sido homogéneo, sino que se destaca la mayor propensión hacia la innovación de las empresas exportadoras grandes.

\section{REFERENCIAS}

\section{Fuentes primarias}

Anuarios Estadísticos. Existencias, Faena y Exportación (INAC).

Anuarios Estadísticos. Existencias, Faena, Precios y Exportación (INAC).

Microdatos de las Encuestas de Actividades de Innovación (ANII).

Microdatos de las Encuestas de Actividad Económica (INE). 


\section{Referencias bibliográficas}

Agencia Nacional de Investigación e Innovación [ANII]. (n.d.). Encuesta de actividades de innovación en la industria manufacturera y servicios seleccionados. Período 2013-2015. https://www. anii.org.uy/institucional/documentos-de-interes/22/ documentos-de-ciencia-tecnologia-e-innovacion/

Agencia Nacional de Investigación e Innovación [ANII]. (2003). El proceso de innovación en la industria uruguaya. Resultados de la Encuesta de Actividades de innovación (1998-2000). ANII. https:// www.anii.org.uy/institucional/documentos-de-interes/22/ documentos-de-ciencia-tecnologia-e-innovacion/

Agencia Nacional de Investigación e Innovación [ANII]. (2006). La innovación en la industria uruguaya (2001-2003). II Encuesta de Actividades de Innovación en la Industria. ANII. https:// www.anii.org.uy/institucional/documentos-de-interes/22/ documentos-de-ciencia-tecnologia-e-innovacion/

Agencia Nacional de Investigación e Innovación [ANII]. (2015). Encuesta de actividades de innovación en la industria manufacturera y servicios seleccionados (2010-2012). Principales resultados. https:// www.anii.org.uy/institucional/documentos-de-interes/22/ documentos-de-ciencia-tecnologia-e-innovacion/

Alfaro, D., \& Olivera, M. (2009). Transmisión de precios y poder de mercado: el caso del ganado vacuno para faena. Ministerio de Economía y Finanzas de Uruguay. https://www.mef.gub.uy/innovaportal/ file/1414/1/20100729_informe_final_mercado_ganado_vacuno_ faena.pdf

Bisang, R., Robert, S., Santangelo, F., \& Albornoz, I. (2008). Estructura de la oferta de carnes bovinas en la Argentina. Actualidad y evolución reciente. Instituto de Promoción de la Carne Vacuna (IPCV) y Oficina de la CEPAL en Buenos Aires. https://www.academia.edu/19784773/ Estructura_de_la_oferta_de_carne_bovina_en_Argentina_ Actualidad_y_evoluci\%C3\%B3n_reciente 
Bittencourt, G., Carracelas, G., \& Lorenzi, N. R. (2011). Determinantes y efectos de la inversión extranjera directa en la industria frigorífica uruguaya (Documento de trabajo N.'2911 Departamento de Economía [dECON]). IDEAS RePEc. http://ideas.repec.org/p/ude/ wpaper/2911.html

Buxedas, M. (1983). La industria frigorífica en el Río de la Plata: 1959-1977. CLACSO. https://www.clacso.org.ar/ libreria-latinoamericana/libro_por_programa_detalle. php?campo=programa\&texto $=20 \& i d \_l i b r o=371$

Comisión Sectorial para el Mercosur [COMISEC]. (1994). Análisis del sector carne bovina. (Centro de Documentación y Difusión, Estudios Técnicos N.12). COMISEC.

Espino, A., \& Salazar, A. (2000). La generación de empleo en los complejos agroindustriales en el Uruguay. Perspectivas a corto y mediano plazo. Comisión Sectorial de Investigación Científica (CSIC) de la Universidad de la República.

Fabani, C. (2011, junio 2). Actividad en la Industria de procesamiento de carnes y sus repercusiones en el empleo; tendencias e implicancias [presentación]. Foro de las carnes, INAC, Montevideo, Uruguay.

Gabinete Productivo (2009). Cadenas de valor (I): carnes, lácteos, granos, maderas, automotriz, farmacéutica, TIC's, energías renovables. Gabinete Productivo. https://pmb.parlamento.gub.uy/pmb/opac_ css/index.php?lvl=notice_display\&id=59855

Geymonat, J. (2019). Industrias e industriales en un contexto de desindustrialización (1980-2015) (tesis de maestría, Universidad de la República, Uruguay). Repositorio institucional de la Universidad de la República. https://www.colibri.udelar.edu.uy/jspui/ handle/20.500.12008/23441

Laens, S., \& Paolino, C. (2004). Estudio de competitividad de cadenas agroindustriales. Cadena de carne vacuna [trabajo sin publicar]. n. d. López, A. (1998). Frigoríficos y Mercados. https://pmb.parlamento.gub.uy/ pmb/opac_css/index.php?lvl=notice_display\&id=30663

Mondelli, M. (2007). Coordenação do sistema agroindustrial da carne bovina: determinantes dos arranjos contratuais entre produtores e processadores no Uruguai (Tesis de maestría, Universidade de São Paulo). Repositorio institucional Universidade de São Paulo. 
Ordeix, M., \& Ferreira, G. (2001). Competitividad y coordinación en la cadena de carne bovina. Instituto de Investigación Agropecuaria. http://www. inia.org.uy/publicaciones/documentos/tb/ad/2002/informe-4.pdf

Paolino, C. (2004, noviembre). Elementos para una evaluación del proyecto de desarrollo ganadero en el Uruguay: un aporte de autores de la Nueva Economía institucional [conferencia]. Segundo Congreso Rioplatense de Economía Agraria, Mar de Plata, Argentina. http://www.ipcva. com.ar/files/trabajo74.pdf

Pérez-Arrarte, C. (1993). La industria frigorífica tras la reconversión productiva. Fundación de Cultura Universitaria.

Rocca, J. A. (n.d.). El complejo de carnes rojas: la estructura de la producción. Uruguay 1975-1987 (tesis de grado, Universidad de la República, Uruguay). Universidad de la República.

Sala, A. (2009). Secretos de familia. Del negocio familiar a la gran multinacional. Robinbook.

Sanguinetti, G. (2013). La Trazabilidad individual bovina en Uruguay como política de innovación tecnológica (período 2004-2012) (tesis de maestría, Facultad Latinoamericana de Ciencias Sociales [FLACSO]). Repositorio Digital FLACSO.

Sanguinetti, G., Garrido, G., Aguirregaray, P., \& Duarte, R. (2018). Prospectiva de formación profesional en el sector de la Industria Frigorífica de Uruguay, especializada en la producción de carne vacuna. Informe final, julio 2018. Organización Internacional del Trabajo \& Centro Interamericano para el Desarrollo del Conocimiento en la Formación Profesional. https://www.oitcinterfor.org/node/7383

Trylesinski, F. (1981). La industria frigorífica como demandante de ganado vacuno: efectos de las medidas de agosto de 1978 (tesis de grado, Universidad de la República, Uruguay). Universidad de la República. 